\title{
Disturbance Attenuation of DC Voltage Droop Control Structures in a Multi-Terminal HVDC Grid
}

Thams, Florian; Chatzivasileiadis, Spyros; Prieto-Araujo, Eduardo; Eriksson, Robert

Published in:

Proceedings of 12th IEEE Power and Energy Society PowerTech Conference

Publication date:

2017

Document Version

Peer reviewed version

Link back to DTU Orbit

Citation (APA):

Thams, F., Chatzivasileiadis, S., Prieto-Araujo, E., \& Eriksson, R. (2017). Disturbance Attenuation of DC Voltage Droop Control Structures in a Multi-Terminal HVDC Grid. In Proceedings of 12th IEEE Power and Energy Society PowerTech Conference IEEE.

\section{General rights}

Copyright and moral rights for the publications made accessible in the public portal are retained by the authors and/or other copyright owners and it is a condition of accessing publications that users recognise and abide by the legal requirements associated with these rights.

- Users may download and print one copy of any publication from the public portal for the purpose of private study or research.

- You may not further distribute the material or use it for any profit-making activity or commercial gain

- You may freely distribute the URL identifying the publication in the public portal 


\section{Disturbance Attenuation of DC Voltage Droop Control Structures in a Multi-Terminal HVDC Grid}

\author{
Florian Thams and Spyros Chatzivasileiadis \\ Center for Electric Power and Energy (CEE) \\ Technical University of Denmark \\ \{fltha\} / \{spchatz\}@elektro.dtu.dk
}

\author{
Eduardo Prieto-Araujo \\ CITCEA-UPC \\ Universitat Politècnica de Catalunya \\ eduardo.prieto-araujo@citcea.upc.edu
}

\author{
Robert Eriksson \\ Market and System Development \\ Svenska Kraftnät \\ robert.eriksson@svk.se
}

\begin{abstract}
DC voltage droop control is seen as the preferred control structure for primary voltage control of future multiterminal HVDC systems. Different droop control structures have been proposed in literature which can be classified in eight categories. This paper contributes to an analysis of the disturbance rejection of these droop control structures. The approach is based on multi-variable frequency response analysis where both ac and dc grid dynamics are incorporated. In particular, the amplification of dc voltage oscillations due to wind power variations is analyzed using singular value analysis. Further, the impact of dc cable modeling on the results is discussed. In addition, it is shown that the maximum singular value limits, frequently used in literature for MIMO-analysis, are not sufficient to prove that the impact of certain disturbances on analyzed outputs is within a certain boundary. It is necessary to verify the results by a multiple input single output analysis of the transfer functions connecting the inputs with the highest amplified output.
\end{abstract}

Index Terms-HVDC transmission, Wind energy integration, Control system analysis, State-space methods

\section{INTRODUCTION}

The present trend of developing offshore wind farms with increasing distance from shore raised the interest in HVDC based on voltage source converters (VSC). VSC-HVDC entails several advantages compared to HVDC based on linecommutated converters such as smaller converter size or the capability to supply weak grids. Further, the ease of changing rapidly the power direction and enabling parallel connections makes VSC-HVDC the most appropriate technology for a multi-terminal HVDC (MT-HVDC) grid. However, only a few multi-terminal VSC-HVDC systems have been built worldwide while many ideas and projects have been proposed [1].

Due to the very little experience with MT-HVDC grids, there is no standardization of the control structure for such grids yet. It is acknowledged in academia and industry that it is preferable to have a distributed control architecture [2], as it makes the grid more resilient against the significant impact of any single malfunction. Thus, it is preferable to have multiple units actively participating in the control of the dc grid voltage instead of having it controlled by a single converter. One of the preferred control structures, enabling power sharing between several converters, is dc voltage droop control. In technical

This work is co-funded by the European Unions Seventh Framework Programme for Research, Technological Development and Demonstration under the grant agreement no. 612748 . literature, however, several alternative droop control schemes have been discussed [3]-[22]. Here, we collect them all and evaluate their performance by their disturbance attenuation.

In general, a droop control scheme introduces a linear relationship between two electrical variables. In the specific case of dc voltage droop control for MT-HVDC, the dc voltage is used in each implementation, so that the droop gain, $k_{d r o o p}$, defines the deviation of $V_{d c}$ for a variation of the other electric variable:

$$
V_{d c}=V_{d c}^{*}+k_{\text {droop }}\left(y^{*}-y\right)
$$

$y^{*}$ and $V_{d c}^{*}$ are the set points and $V_{d c}, y$ are the measured electric variables respectively. The second electric variable, $y$, can either represent the dc current, $I_{d c}$, one component of the ac current, $I_{a c}$, the active power measured on the dc side, $P_{d c}$, or the active power measured on the ac side, $P_{a c}$. They can be categorized by two different types of generalized structures, depending on whether the dc voltage is used within the first loop (Type2 $\left.\left(V_{d c}-y\right)\right)$ or the second loop (Type1 $\left.\left(y-V_{d c}\right)\right)$ as shown in Fig. 1. This leads to a total of 8 different de voltage droop control structures, shown in Fig. 2.

In [9] a methodology was proposed to analyse the multivariable frequency response for one specific dc voltage droop control structure (CS). This work was extended in [23] using the methodology to design a droop controller using certain requirements based on maximum singular value (SV) limits. However, to the knowledge of the authors no previous work is done on analysing and comparing the performance of all the different CSs in terms of multi-variable frequency response.

The contributions of this paper include the following: First, we perform an analysis and comparison of the multi-variable frequency response of the eight different CSs. Second, we compare the results for a frequency dependent and a conventional $\pi$-equivalent dc cable model indicating how the usage of the latter might lead to overrated resonance peaks. We also perform a participation factor analysis of the eigenvalues

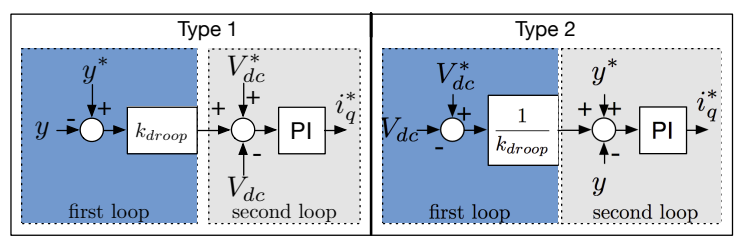

Fig. 1. Generalized droop control structures. 


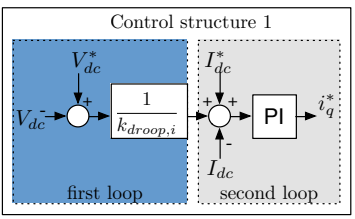

(a) $\operatorname{CS} 1\left(V_{d c}-I_{d c}\right)-[3]-[9]$.

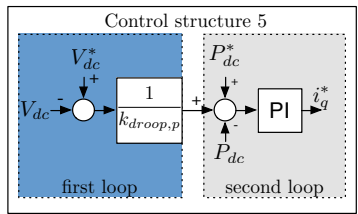

(e) $\operatorname{CS5}\left(V_{d c}-P_{d c}\right)-[17]-[20]$

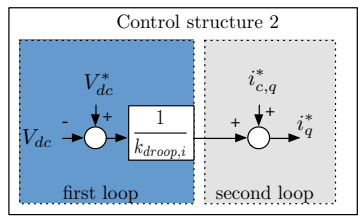

(b) $\operatorname{CS} 2\left(V_{d c}-I_{a c}\right)-[10],[11]$

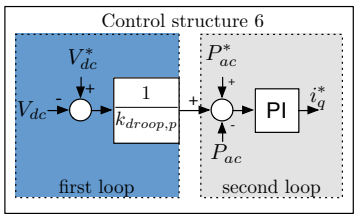

(f) $\operatorname{CS6}\left(V_{d c}-P_{a c}\right)-[20]$.

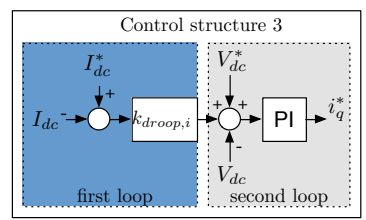

(c) $\operatorname{CS} 3\left(I_{d c}-V_{d c}\right)-[12]-[14]$.

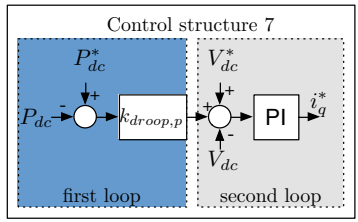

(g) CS7 $\left(P_{d c}-V_{d c}\right)-[21],[22]$

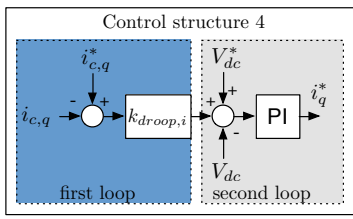

(d) CS4 $\left(I_{a c}-V_{d c}\right)-[15]$.

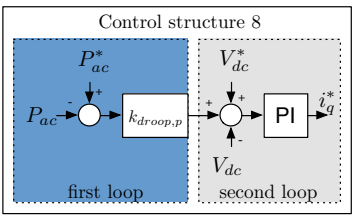

(h) $\operatorname{CS} 8\left(P_{a c}-V_{d c}\right)-[22]$.

Fig. 2. Analysed dc voltage droop control structures.

corresponding to the resonance peaks in order to determine the origin of resonance peaks observed in the singular value representation. Third, we point out that the maximum SV limits frequently used for multiple input multiple output (MIMO) analysis in literature (e.g. [23], [24]) are not sufficient to prove that the impact of specific disturbances on analyzed outputs is within a certain boundary. Due to the fact that these maximum SV limits implicitly assume the same amplification at every output, it is necessary to verify them by a multiple input single output (MISO) analysis of the transfer functions connecting the inputs with the highest amplified output.

This paper is structured as follows: First, the methodology will be introduced, then the analyzed model will be presented followed by a discussion of the results.

\section{Methodology}

The methodology enables the analysis of the different dc voltage droop control structures considering all the dynamics of a generic multi-terminal HVDC system. The control structure of a generic multi-terminal HVDC system is illustrated in Fig. 3. The wind farms are assumed to control the ac grid voltage and angle and to export all available active power. Thus their active power in-feed into the dc grid is considered as uncontrolled disturbance for the distributed droop voltage control scheme. Based on this scheme the closed loop transfer function matrices combining the converters and both ac and dc grid dynamics can be calculated:

$$
\begin{aligned}
\mathbf{E}_{w}(s) & =\frac{\mathbf{z}(s)}{\mathbf{w}(s)}=\frac{\left(\Delta V_{d c, 1}(s) \cdots \Delta V_{d c, M}(s)\right)^{T}}{\left(P_{w f, N+1}(s) \cdots P_{w f, M}(s)\right)} \\
\mathbf{U}_{w}^{u i q}(s) & =\frac{\mathbf{u}_{i q}(s)}{\mathbf{w}(s)}=\frac{\left(i_{c, 1}^{q *}(s) \cdots i_{c, N}^{q *}(s)\right)^{T}}{\left(P_{w f, N+1}(s) \cdots P_{w f, M}(s)\right)}
\end{aligned}
$$

where $\mathbf{E}_{w}(s)$ is the transfer function matrix relating the power induced into the HVDC grid by the wind farms, $\mathbf{w}_{i}$, with the dc voltage deviations at all terminals, $\mathbf{z}_{i}$, with $k=1 \ldots N$ representing the grid side converters (GSCs) while $k=N+1 \ldots M$ resemble the connected wind farms. The transfer function matrix $\mathbf{U}_{w}^{u i q}(s)$ relates accordingly the wind farm power, $\mathbf{w}$, with $\mathbf{u}_{i q}$, the active current loop references of the current loops of the different GSCs.

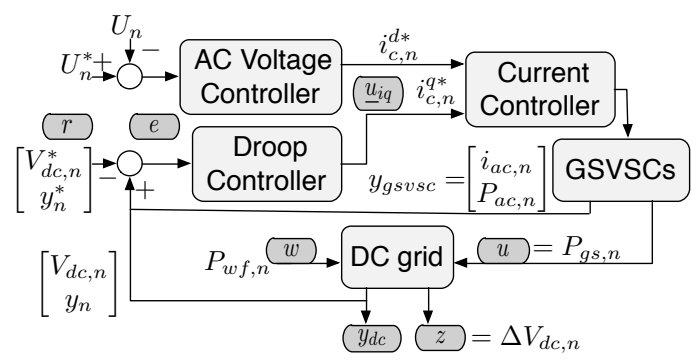

Fig. 3. Control structure of multi-terminal HVDC grid.

The performance of the control structures is analysed by means of the singular value representation of the system transfer function matrix, $\mathbf{E}_{w}(s)$, which can be obtained as:

$$
\sigma_{i}\left(\mathbf{E}_{w}(j \omega)\right)=\sqrt{\lambda_{i}\left(\mathbf{E}_{w}^{T}(j \omega) \mathbf{E}_{w}(j \omega)\right)}
$$

where $\lambda_{i}$ is the $i$-eigenvalue of the matrix. The maximum SV $\bar{\sigma}\left(\mathbf{E}_{w}(j \omega)\right)$ indicates the maximum amplification of the corresponding inputs by the system seen from a specific output. Here, we analyse which effect the wind power input (w in Fig. 3) has on the de voltage deviations (z) at all HVDC terminals. Thus, according to [23], in case a maximum voltage error of $10 \%\left(\epsilon_{v}\right)$ of the nominal value at each terminal should not be exceeded, the maximum singular value $\bar{\sigma}\left(\mathbf{E}_{w}(j \omega)\right)$ can be derived as:

$\bar{\sigma}\left(\mathbf{E}_{w}(j \omega)\right) \leq \frac{\|\mathbf{z}(j \omega)\|_{2}}{\|\mathbf{w}(j \omega)\|_{2}}=20 \log _{10}\left(\frac{\sqrt{\sum_{k=1}^{M}\left(V_{d c, k} \cdot \epsilon_{v}\right)^{2}}}{\sqrt{\sum_{k=N+1}^{M} P_{w f, k}^{2}}}\right)$

In addition, in [23] the authors derive the maximum gain the SV representation of the transfer function $\mathbf{U}_{r}^{u i q}(j \omega)$ should not exceed. As given in (3), these transfer functions indicate the impact of the wind power in-feed on the active current loop references of the different GSCs. This maximum gain corresponds to a maximum allowed current flowing through 
the GSCs of $110 \%\left(\epsilon_{i}\right)$ of the nominal current value, $i_{n}$.

$\bar{\sigma}\left(\mathbf{U}_{w}^{u i q}(j \omega)\right) \leq \frac{\left\|\mathbf{u}_{i q}(j \omega)\right\|_{2}}{\|\mathbf{w}(j \omega)\|_{2}}=20 \log _{10}\left(\frac{\sqrt{\sum_{k=1}^{N}\left(i_{n, k} \cdot \epsilon_{i}\right)^{2}}}{\sqrt{\sum_{k=N+1}^{M} P_{w f, k}^{2}}}\right)$

However, by using the $L_{2}$-norm these limits calculate the maximum energy of the error caused by the disturbances that would lead to a $10 \%$ voltage deviation / $110 \%$ nominal current at each terminal. Hence, these limits assume implicitly that the deviation of the outputs is the same for all outputs, i.e. e.g. the dc voltage deviation is the same at each terminal in the whole grid. However, this is not true and since the exact deviation at the less deviating terminals is not known in advance it can therefore not be considered in the calculation. Therefore, we will show that it is necessary to validate the results by analysing the transfer functions from the chosen disturbances to that output which experiences the highest deviation. That means, to calculate the maximum error, $\epsilon$, of the most deviating output by using $\bar{\sigma}$ of the MISO analysis to solve (5) and (6) for $\epsilon$ while neglecting the sum in the numerator considering only the single most deviating output.

Extending the SV analysis, we analyzed the eigenvalues, $\lambda_{i}$, in terms of their damping ratio, $\zeta$, and damped circular frequency, $\omega_{d}$, in order to determine those eigenvalues corresponding to the resonance peaks in the SV representation. Then, we derived the participation matrix, $\Gamma$, enabling us to detect the participation factor, $\Gamma_{k i}$, of the $k$-state in the $i$-th mode [25]:

$$
\boldsymbol{\Gamma}=\left\{\Gamma_{k i}\right\}=\left\{v_{k i} l_{i k}\right\}
$$

where $v_{k i}$ and $l_{k i}$ are the k-th entry of the i-th right $\left(\mathbf{v}_{\mathbf{i}}\right)$ respective left $\left(\mathbf{l}_{\mathbf{i}}\right)$ eigenvectors of $\mathbf{A}$. Hence, the participation factor analysis allows to determine the origin of the resonance peaks.

\section{Modeling}

The modeling is done according to the generic multiterminal grid derived in [23]. A three terminal grid is used as case study with two GSCs connected by LC filters to two different equivalent ac grids, modeled as Thévenin equivalent. An overview is shown in Fig. 4. The GSCs are assumed to be synchronized to the ac grids through a Phase Locked Loop (PLL) and operated with conventional current controllers in the Synchronous Reference Frame (SRF). The current controllers of the GSCs are tuned by the Internal Model Control (IMC) technique designed to track references with a settling time

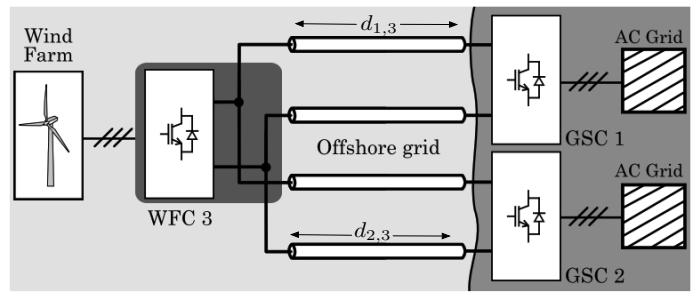

Fig. 4. Three terminal VSC-HVDC grid [23]. of $10 \mathrm{~ms}$ [26]. Saturation limits are included in the control scheme, in order not to exceed the maximum current ratings of the converters. Both GSCs are assumed to use one of the eight dc voltage droop control structures, shown in Fig. 2. In order to achieve a comparable performance of power and current based droop control structures, the following is done:

- The droop gains were chosen as $k_{d r o o p, p}=\frac{1}{25} \frac{\mathrm{V}}{\mathrm{kW}}$ as suggested in [23].

- The droop gains used within the power and current based droop controller should be comparable. Thus, the relation derived in [27] and given in (8) is used to determine the current based droop gains, $k_{d r o o p, i i_{d c}}$, that are equivalent to the power based droop gains, $k_{d r o o p, p}$. The current based droop gain used for the CSs combining $V_{d c}$ and $I_{a c}$ needs to be scaled additionally (9), due to the higher range of $I_{a c}$. However, due to the non-linearity of power based droop control, the approximation holds only for a small deviation of the voltage.

$$
\begin{aligned}
k_{d r o o p, i_{d c}} & =\frac{V_{d c}^{*}}{\frac{1}{k_{d r o o p, p}}-I_{d c}^{*}} \\
k_{d r o o p, i_{a c}} & =\frac{I_{d c}^{*}}{i_{c, q}^{*}} \cdot k_{d r o o p, i_{d c}}
\end{aligned}
$$

- The tuning of the outer controllers is based on optimization based robust control techniques [28] determining the tuning of the controllers $K(s)$ minimizing the $H_{\infty}$ norm $\left\|T_{w, r \rightarrow y}(K)\right\|_{\infty}$, where $T_{w, r \rightarrow y}(K)$ denotes the closed loop transfer functions from the disturbance, $w$, respectively the references, $\mathbf{r}$, to the measurements, $\mathbf{y}$. A comparable tuning for a chosen settling time of $100 \mathrm{~ms}$ [26] was achieved using pre- and post-compensators.

Only the response of $\operatorname{CS} 2\left(V_{d c}-I_{a c}\right)$ differs, due to the absence of a PI controller, since the droop gain already serves as proportional controller connecting $V_{d c}$ and $i_{q}$ creating the necessary reference variable for the current controller. Hence, the dynamics of $\operatorname{CS} 2\left(V_{d c}-I_{a c}\right)$ are determined by the current controller, which was tuned independently of the outer CS.

The impact of two different dc line models are compared. First, the results are discussed for a conventional $\pi$-equivalent model from the Cigré B4 DC grid test system, in which the capacitors at both ends are the results of incorporating all capacitors connected in parallel. This is a simplified model, but it is considered appropriate, as D'Arco also argues in [29], since the chosen model represents the worst case scenario with respect to LC oscillations. This is due to the fact that the oscillatory effects are condensed in a single frequency, instead of being spread on several frequencies as

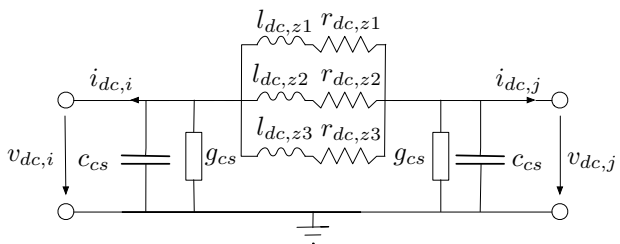

Fig. 5. Approximation of frequency dependent $\pi$ dc cable model [30]. 


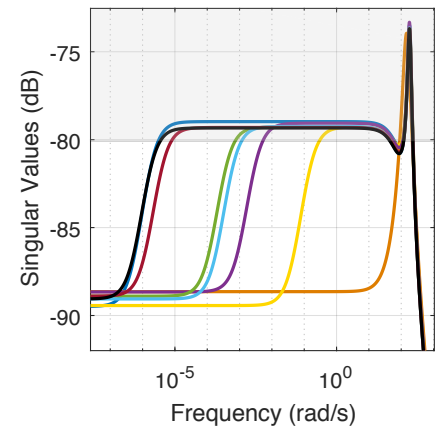

(a)

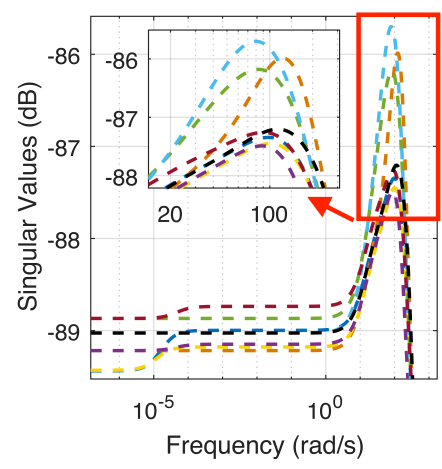

(b)

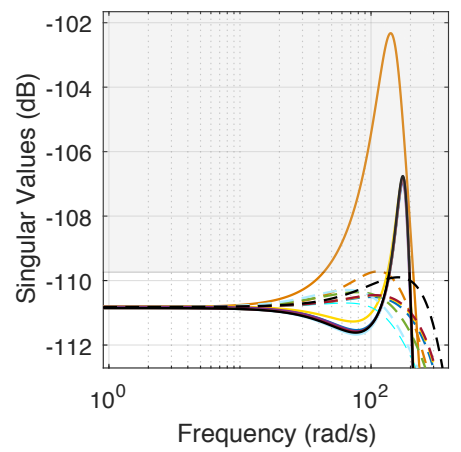

(c)

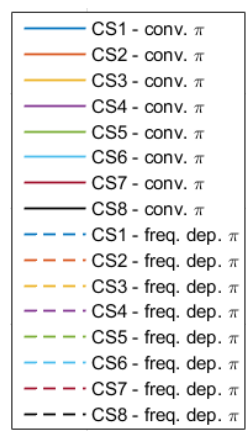

(d)

Fig. 6. Singular value representation of a) $E_{w}(j \omega)$ (wind power input - dc voltage deviation) for a $\pi$-equivalent dc cable model and b) $E_{w}(j \omega)$ for a 'frequency dependent $\pi$ ' cable model, c) $\left.\mathbf{U}_{r}^{u i q}(j \omega)\right)$ (wind power input - current controller reference) for both models and d) the legend for all graphs.

in a real cable. The model parameters are chosen according to [23]. In [24], however, the authors argue that for SVD studies the conventional $\pi$ model may not be accurate enough. Therefore, in a second step, the results are compared to the case where a 'frequency dependent $\pi$ ' cable model, introduced in [30], is implemented. The model, shown in Fig. 5, is called 'frequency dependent $\pi$ ' since the additional parallel branches are calculated to fit the frequency response of a wide-band cable model [24], [31].

\section{CASE STUdy}

The analysis is performed for a scenario where both GSCs use the same dc voltage droop control structure and the same droop gain values. The results are compared for the different dc cable models and examined with a participation factor analysis in order to detect the origin of the resonance peaks.

The wind farm is assumed to inject maximum power into the HVDC grid, since this leads to the highest gains of the SV representation. Thus, it represents the worst case scenario. The linearized model is verified by an equivalent non-linear model built in Matlab Simulink, which also provides the steady state initial values.

The results of the SV analysis of $\mathbf{E}_{w}(j \omega)$ and $\mathbf{U}_{r}^{u i q}(j \omega)$ for both dc cable models are shown in Fig. 6. The maximum SV leading to a max. of $10 \%$ voltage deviation at each terminal and to max. $110 \%$ of the nominal current flowing through the GSCs have been calculated as $\bar{\sigma}\left(\mathbf{E}_{w}(j \omega)\right) \leq-80.09 \mathrm{~dB}$ and $\bar{\sigma}\left(\mathbf{U}_{w}^{u i q}(j \omega)\right) \leq-109.74 \mathrm{~dB}$. The area exceeding those limits has been faded gray in Fig. 6.

\section{A. Cable model: conventional $\pi$}

The SV representations of $\mathbf{E}_{w}(j \omega)$ (Fig. 6a) are very similar for all CSs besides $\operatorname{CS} 2\left(V_{d c}-I_{a c}\right)$, which, however, is the only droop control structure without a PI-controller. All CSs besides $\operatorname{CS} 2\left(V_{d c}-I_{a c}\right)$ exceed the limit of $-80.09 \mathrm{~dB}$ already for $\omega \ll 1$ with values around $-79.3 \mathrm{~dB}$. $\operatorname{CS} 2\left(V_{d c}-I_{a c}\right)$ stays at approx. $-89 \mathrm{~dB}$ for $\omega \leq 1$. For higher frequencies the SV representations of all CSs indicate a peak at a resonance frequency: $\mathrm{CS} 2\left(V_{d c}-I_{a c}\right)$ at $145.5 \mathrm{rad} / \mathrm{s}(=23.2 \mathrm{~Hz})$, all remaining CSs: at approx. $180 \mathrm{rad} / \mathrm{s}(=28.6 \mathrm{~Hz})$. Here, all CSs exceed the limit with a maximum $\bar{\sigma}\left(\mathbf{E}_{w}(j \omega)\right)$ of approx. $-73.6 \mathrm{~dB}$. Hence, all CSs would exceed the limit of a maximum dc voltage deviation of $10 \%$ in case those frequencies are excited.

The SV representations of $\mathbf{U}_{r}^{u i q}(j \omega)$ (Fig. 6c) show that all CSs achieve in steady state a $\bar{\sigma}\left(\mathbf{U}_{r}^{u i q}(j \omega)\right)$ of $-110.8 \mathrm{~dB}$. Thus, all CSs comply with the limit. However, similar to the previous analysis, the SV representations of $\mathbf{U}_{r}^{u i q}(j \omega)$ indicate a resonance peak for all CSs at the same resonance frequencies leading to maximum SVs of $-102.2 \mathrm{~dB}\left(\mathrm{CS} 2\left(V_{d c}-I_{a c}\right)\right)$ to $-106.8 \mathrm{~dB}$ (all remaining CSs). Thus, none of the CSs complies with the limit for the whole frequency range.

The deviation from the results obtained in [23], where only CS6 $\left(V_{d c}-P_{a c}\right)$ was analyzed, are due to the varied cable length (here $d_{1,3}=200 \mathrm{~km}, d_{2,3}=300 \mathrm{~km}$ instead of $d_{1,3}=100 \mathrm{~km}, d_{2,3}=150 \mathrm{~km}$ ) as well as the fact that the $\mathrm{dc}$ voltage deviation at the wind farm is also considered. Here, a smaller droop gain would be necessary to comply with the derived limits. Hence, the analysis shows that with this cable model the choice of the droop gains is closely related to the length of the cables as well as the capacitance size of the wind farm converter.

In the SISO case, the SV analysis is equivalent to the bode diagram of the corresponding transfer function. In the MIMO case, however, the maximum SV is the maximum gain for any input direction, hence the SV representation is not just the sum of the bode diagrams of the corresponding transfer functions. Nevertheless, it is possible to determine the eigenvalues causing the resonance peaks by examining the damped circular frequencies and ratios of the corresponding transfer functions. The corresponding eigenvalues have been examined by a participation factor analysis in order to identify the source of the resonance peak. The analysis is done for the case where both GSCs use $\operatorname{CS} 1\left(V_{d c}-I_{d c}\right)$. However, further analyses showed that the results can be generalized for the remaining CSs.

The analyses showed that the resonance peak of $\operatorname{CS} 1\left(V_{d c^{-}}\right.$ $\left.I_{d c}\right)$ in Fig. 6a is related to a pair of complex eigenvalues, with a damping ratio of $14.5 \%$. The participation factor analysis of this pair of complex eigenvalues causing the resonance peak is shown in Fig. 7. It indicates, that the peak is mainly related to the dc voltage at the wind farm, $V_{d c, 3}$, the currents in the 


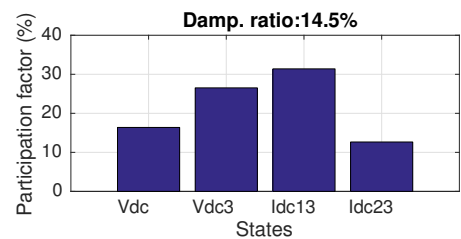

Fig. 7. Participation factor analysis of the complex pair of eigenvalues causing the resonance peak in case of $\operatorname{CS} 1\left(V_{d c}-I_{d c}\right)$.

dc lines, $I_{d c, 13}$ and $I_{d c, 23}$ as well as the dc voltage at GSC1, $V_{d c}$. Similar results with varying damping ratios are obtained for the analysis of the resonance peaks of the remaining CSs. Hence, the resonance peaks, i.e. the maximum possible amplifications of dc voltage oscillations, are always related to $\mathrm{dc}$ values at the wind farm. The results are also similar for the analysis of eigenvalues corresponding to the peaks of the SV representation of the transfer function matrix $\mathbf{U}_{w}^{u i q}(s)$, which resembles the control action. Hence, in contrast to the usual practice that the wind farm converter does not participate in the dc voltage control, the results indicate that a participation or an additional damping of dc voltage oscillations at this point could be feasible.

\section{B. Cable model: frequency dependent $\pi$}

The frequency dependent $\pi$ model enables the droop control structures to react faster without causing instability, which results in a better disturbance attenuation. Hence, the results for $E_{w}(j \omega)$ (Fig. 6b) indicate lower SVs for the whole frequency range for all CSs, however, with slightly bigger differences between them. While in steady state, the maximum $\mathrm{SVs}$ of all CSs are comparable, with $\operatorname{CS} 1\left(V_{d c}-I_{d c}\right)$ achieving the lowest with $-89.5 \mathrm{~dB}$. The differences are caused by the different tunings and the fact that (8) is only an approximation of the non-linear control behavior of active power and $\mathrm{dc}$ voltage [27].

For frequencies $\geq 10 \frac{\mathrm{rad}}{\mathrm{s}}, \operatorname{CS} 4\left(I_{a c}-V_{d c}\right)$ achieves the lowest $\bar{\sigma}\left(\mathbf{E}_{w}(j \omega)\right)$ with $-87.49 \mathrm{~dB}$ at a frequency of $88 \mathrm{rad} / \mathrm{s}$ $(=14 \mathrm{~Hz})$. The highest maximum singular value is obtained by CS6 $\left(V_{d c}-P_{a c}\right)$ with $-85.7 \mathrm{~dB}$, closely followed by $\operatorname{CS} 2\left(V_{d c^{-}}\right.$ $\left.I_{a c}\right)(-85.99 \mathrm{~dB})$ and $\mathrm{CS} 5\left(V_{d c}-P_{d c}\right)(-86.18 \mathrm{~dB})$.

Although it seems, as if all CSs stay far below the $10 \%$ voltage deviation limit $(-80.09 \mathrm{~dB})$, it is not possible to calculate the maximum dc voltage deviation from these $\mathrm{dB}$ values using (5), since the dc voltage deviation at each converter differs. Assuming the same deviation for all outputs, as (5) and (6) do, a maximum deviation of $4.27 \%\left(\mathrm{CS} 4\left(I_{a c}-V_{d c}\right)\right)$ and $5.26 \%\left(\mathrm{CS} 6\left(V_{d c}-P_{a c}\right)\right)$ would be achieved. However, the deviations are not the same, in fact, the highest deviation can be observed at the wind farm, due to the fact that there is no dc voltage control at this point and the input is not damped by a cable. Hence, if we only consider the transfer function from wind power input to dc voltage deviation at the wind farm converter we can calculate a maximum voltage deviation of $5.74 \%\left(\mathrm{CS} 4\left(I_{a c}-V_{d c}\right)\right)$ and $6.73 \%\left(\mathrm{CS} 6\left(V_{d c}-P_{a c}\right)\right)$ using (5). Thus, in contrast to what is implicitly assumed in (5) and (6), when deriving a maximum SV limit in the MIMO analysis, it always needs to be considered that the output deviation might not be the same at every output. Since the deviation at the less deviating terminals is not known in advance and can therefore not be considered in the calculation, the transfer functions from the disturbances to the highest deviating output (MISO analysis) should be analysed additionally in order to verify the results.

The analysis of the control action, i.e. the SV representation of $\mathbf{U}_{w}^{u i q}(j \omega)$ (Fig. 6c), for the various CSs indicates small differences between the different CSs. Here, only $\operatorname{CS} 2\left(V_{d c}-\right.$ $I_{a c}$ ) exceeds the limit of $-109.74 \mathrm{~dB}$ slightly. Although the remaining CSs do not exceed the limit, it is necessary to analyse the transfer function from the wind power input to the highest deviating output, the current reference at the converter station closest to the wind farm, GSC1. It indicates that only $\operatorname{CS} 4\left(I_{a c}-V_{d c}\right)$ would comply with the boundary of max. $110 \%$ of the nominal current flowing through GSC1. While - in case the frequencies corresponding to the resonance peaks are excited by the input signal - the current exceeds from $111 \%$ $\left(\mathrm{CS} 5\left(V_{d c}-P_{d c}\right)\right)$ up to $120 \%\left(\operatorname{CS} 8\left(P_{a c}-V_{d c}\right)\right)$ of the nominal current for the remaining CSs.

Analysing the eigenvalues of $\operatorname{CS} 1\left(V_{d c}-I_{d c}\right)$, a complex pair of eigenvalues with similar participation factors as the one leading to the resonance peak in the conventional $\pi$ model can be identified at the damping frequency of $327.44 \mathrm{rad} / \mathrm{s}$ $(=52.1 \mathrm{~Hz})$ with a damping ratio of $52.2 \%$. Hence, the different dc cable parameters lead to a change in the resonance frequency and a significantly higher damping.

\section{Discussion}

The results show that it is important to use a more accurate frequency dependent cable model as it allows to perform a more accurate design of the distributed droop voltage control.

Further, it was shown that the maximum dc voltage deviation depends on the chosen dc voltage droop CS. In fact, for the topology chosen in the case study it can be minimized to $5.74 \%$ by using $\operatorname{CS} 4\left(I_{a c}-V_{d c}\right)$ instead of $6.73 \%$ with CS6 $\left(V_{d c}-P_{a c}\right)$, which would allow the operator to operate the system closer to the nominal values, thus more efficiently.

Only $\operatorname{CS} 4\left(I_{a c}-V_{d c}\right)$ managed to comply also with the requirement of limiting the current flowing through the GSCs to $110 \%$ of the nominal current. The choice of a higher droop gain would allow all CSs to comply with that requirement, however, at the same time it would increase the dc voltage deviation. The effect is the same for all CSs, hence, the differences between them are comparable for different droop gains. Finally, the need for MISO analyses due to varying impact of the disturbance on the different HVDC terminals has been highlighted.

\section{CONCLUSION}

The impact of the various dc voltage droop control structures has been compared for two different dc cable models. It was shown that the possible amplification of dc oscillations depends up to a certain extent on the chosen dc voltage droop control structure. Finally, we showed that the maximum singular value limits, frequently used in literature for MIMO 
analysis, is not sufficient to prove that the impact of specific disturbances on analyzed outputs is within a certain boundary. In fact, it is necessary to verify them by an analysis of the transfer functions connecting the disturbances with the highest deviating output (MISO analysis) due to an uneven impact of the disturbances on the different outputs.

\section{REFERENCES}

[1] D. V. Hertem, O. Gomis-Bellmunt, and J. Liang, Eds., HVDC grids: for offshore and supergrid of the future. Wiley-IEEE Press, 2016.

[2] V. Akhmatov, M. Callavik, C. M. Franck, S. E. Rye, T. Ahndorf, M. K. Bucher, H. Muller, F. Schettler, and R. Wiget, "Technical guidelines and prestandardization work for first HVDC Grids," IEEE Transactions on Power Delivery, vol. 29, no. 1, 2014

[3] C. D. Barker and R. Whitehouse, "Autonomous converter control in a multi-terminal HVDC system," in 9th IET International Conference on AC and DC Power Transmission, London, 2010, pp. 1-5.

[4] W. Wang, M. Barnes, and O. Marjanovic, "Droop control modelling and analysis of multi-terminal VSC-HVDC for offshore wind farms," in 10th IET Int. Conf. on AC and DC Power Transmission, Birmingham, 2012.

[5] O. Gomis-Bellmunt, J. Liang, J. Ekanayake, and N. Jenkins, "Voltagecurrent characteristics of multiterminal HVDC-VSC for offshore wind farms," Elec.Power Syst. Research, vol. 81, no. 2, pp. 440-450, 2011.

[6] L. Xu, L. Yao, and M. Bazargan, "DC grid management of a multiterminal HVDC transmission system for large offshore wind farms," in Int. Conf. on Sust. Power Gen. and Supply, 2009, pp. 1-7.

[7] F. D. Bianchi and O. Gomis-Bellmunt, "Droop control design for multiterminal VSC-HVDC grids based on LMI optimization," in 50th IEEE Conf. on Decision and Control and Europ. Control Conf., Orlando, 2011.

[8] L. Xu and L. Yao, "DC voltage control and power dispatch of a multi-terminal HVDC system for integrating large offshore wind farms," Renewable Power Generation, IET, vol. 5, no. 3, pp. 223-233, 2011.

[9] E. Prieto-Araujo, F. D. Bianchi, A. Junyent-Ferre, and O. GomisBellmunt, "Methodology for Droop Control Dynamic Analysis of Multiterminal VSC-HVDC Grids for Offshore Wind Farms," IEEE Transactions on Power Delivery, vol. 26, no. 4, pp. 2476-2485, 2011.

[10] R. T. Pinto, S. Rodrigues, P. Bauer, and J. Pierik, "Operation and control of a multi-terminal DC network," in IEEE ECCE Asia Downunder, Melbourne, 2013, pp. 474-480.

[11] Y. Chen, G. Damm, and A. Benchaib, "Multi-Time-Scale Stability Analysis and Design Conditions of a VSC Terminal with DC Voltage Droop Control for HVDC Networks," in 53rd IEEE Conference on Decision and Control, Los Angeles, CA, 2014.

[12] J. Liang, T. Jing, O. Gomis-Bellmunt, J. Ekanayake, and N. Jenkins, "Operation and Control of Multiterminal HVDC Transmission for Offshore Wind Farms," IEEE Transactions on Power Delivery, vol. 26 no. 4, pp. 2596-2604, 2011.

[13] B. K. Johnson, R. H. Lasseter, F. L. Alvarado, and R. Adapa, "Expandable multiterminal dc systems based on voltage droop," IEEE Transactions on Power Delivery, vol. 8, no. 4, 1993.

[14] S. Zhou, J. Liang, J. B. Ekanayake, and N. Jenkins, "Control of multiterminal VSC-HVDC transmission system for offshore wind power generation," in 44th Int. Universities Power Eng. Conf., Glasgow, 2009.

[15] F. Thams, J. A. Suul, S. D'Arco, M. Molinas, and F. W. Fuchs, "Stability of DC Voltage Droop Controllers in VSC HVDC Systems," in PowerTech, Eindhoven 2015, Eindhoven, 2015.

[16] F. Thams, R. Eriksson, and M. Molinas, "Interaction of Droop Control Structures and its Inherent Effect on the Power Transfer Limits in Multiterminal VSC-HVDC," IEEE Transactions on Power Delivery, vol. 32, no. 1, pp. 182-192, 2017.

[17] P. Rault, F. Colas, X. Guillaud, and S. Nguefeu, "Method for small signal stability analysis of VSC-MTDC grids," in IEEE Power and Energy Society General Meeting, San Diego, 2012.

[18] J. Dragon, L. Werner, and J. Hanson, "Effects of DC Voltage Droop Characteristics on Contingency Behaviour of AC / DC Systems," in 49th Int. Universities' Power Eng. Conf. (UPEC), Cluj-Napoca, 2014.

[19] T. M. Haileselassie and K. Uhlen, "Impact of DC Line Voltage Drops on Power Flow of MTDC Using Droop Control," IEEE Transactions on Power Systems, vol. 27, no. 3, pp. 1441-1449, 2012.

[20] T. M. Haileselassie and K. Uhlen, "Precise control of power flow in multiterminal VSC-HVDCs using DC voltage droop control," in IEEE Power and Energy Society General Meeting, San Diego, 2012.
[21] T. M. Haileselassie and K. Uhlen, "Primary frequency control of remote grids connected by multi-terminal HVDC," in IEEE Power and Energy Society General Meeting, Minneapolis, 2010, pp. 1-6.

[22] G. Stamatiou and M. Bongiorno, "Decentralized converter controller for multiterminal HVDC grids," in 15th European Conference on Power Electronics and Applications (EPE), 2013, pp. 1-10.

[23] E. Prieto-Araujo, A. Egea-Alvarez, S. F. Fekriasl, and O. GomisBellmunt, "DC voltage droop control design for multi-terminal HVDC systems considering AC and DC grid dynamics," IEEE Transactions on Power Delivery, vol. 31, no. 2, pp. 575 - 585, 2015.

[24] S. Akkari, E. Prieto-Araujo, J. Dai, O. Gomis-Bellmunt, and X. Guillaud, "Impact of the DC cable models on the SVD analysis of a MultiTerminal HVDC system," in 19th Power Systems Computation Conference (PSCC), Genoa, 2016, pp. 1-6.

[25] I. J. Perez-Arriaga, G. C. Verghese, and F. C. Schweppe, "Selective Modal Analysis with Applications to Electric Power Systems, Part I: Heuristic Introduction," IEEE Power Engineering Review, vol. PER-2, no. 9 , pp. 29-30, 1982 .

[26] H. Saad, X. Guillaud, J. Mahseredjian, S. Dennetiere, and S. Nguefeu, "MMC Capacitor Voltage Decoupling and Balancing Controls," IEEE Transactions on Power Delivery, vol. 30, no. 2, pp. 704-712, 2014.

[27] T. K. Vrana, "System Design and Balancing Control of the North Sea Super Grid," Ph.D. dissertation, NTNU, Trondheim, 2013.

[28] P. Apkarian, V. Bompart, and D. Noll, "Non-smooth structured control design with application to PID loop-shaping of a process," Int. J. Robust Nonlinear Control, no. 17, 2007.

[29] S. D'Arco, J. A. Suul, and M. Molinas, "Implementation and Analysis of a Control Scheme for Damping of Oscillations in VSC-based HVDC Grids," in 16th International Power Electronics and Motion Control Conference and Exposition, Antalya, Turkey 21-24, 2014, pp. 586-593.

[30] J. Beerten, S. D'Arco, and J. A. Suul, "Frequency-dependent cable modelling for small-signal stability analysis of VSC-HVDC systems," IET Generation, Transmission \& Distribution, vol. 10, no. 6, 2016.

[31] O. Ramos-Leanos, J. L. Naredo, J. Mahseredjian, C. Dufour, J. A. Gutierrez-Robles, and I. Kocar, "A wideband line/cable model for realtime simulations of power system transients," IEEE Transactions on Power Delivery, vol. 27, no. 4, pp. 2211-2218, 2012.

[32] T. K. Vrana, Y. Yang, D. Jovcic, S. Dennetière, J. Jardini, and H. Saad, "The CIGRE B4 DC Grid Test System," Cigre, Tech. Rep., 2013.

[33] L. Zhang, "Modeling and control of VSC-HVDC links connected to weak AC systems," Ph.D. dissertation, 2010.

\section{APPENDIX}

TABLE I

PARAMETERS OF THE THREE-TERMINAL DC GRID. CIGRÉ B4 DC GRID TEST SYSTEM [32] AND AC GRIDS [33]

\begin{tabular}{ccc}
\hline Parameters & Value & Units \\
\hline Line resistance $r_{d c}$ & 0.0095 & $\Omega / \mathrm{km}$ \\
Line inductance $l_{d c}$ & 2.112 & $\mathrm{mH} / \mathrm{km}$ \\
Line capacitance $c_{c s}$ & 0.1906 & $\mu \mathrm{F} / \mathrm{km}$ \\
Cable distance $d 13$ & 200 & $\mathrm{~km}$ \\
Cable distance $d 23$ & 300 & $\mathrm{~km}$ \\
GSC/WFC DC link capacitor $c_{d c}$ & 150 & $\mu \mathrm{F}$ \\
WFC rated power $P_{3}$ & 700 & $\mathrm{MW}$ \\
Reference voltage $E^{*}$ & 400 & $\mathrm{kV}$ \\
Nominal power $P_{1}, P_{2}$ & 350 & $\mathrm{MW}$ \\
Nominal voltage $V_{a c}$ & 195 & $\mathrm{kV}$ \\
Nominal frequency $f$ & 50 & $\mathrm{~Hz}$ \\
Short circuit ratio $(\mathrm{SCR})$ & 5 & - \\
Grid Thévenin $X_{n} / R_{n}$ ratio & 10 & - \\
Coupling inductance $L_{c}$ & 0.2 & $\mathrm{pu}$ \\
Coupling resistance $R_{c}$ & 0.01 & $\mathrm{pu}$ \\
Capacitor filter impedance $X_{f}$ & 5.88 & $\mathrm{pu}$ \\
\hline
\end{tabular}

TABLE II

PARAMETERS OF THE FREQ. DEPENDENT CABLE MODEL [24]

\begin{tabular}{cc}
$r_{d c, z 1}=1.1724 \cdot 10^{-1} \Omega / \mathrm{km}$ & $l_{d c, z 1}=2.2851 \cdot 10^{-4} \mathrm{H} / \mathrm{km}$ \\
$r_{d c, z 2}=8.2072 \cdot 10^{-2} \Omega / \mathrm{km}$ & $l_{d c, z 2}=1.5522 \cdot 10^{-3} \mathrm{H} / \mathrm{km}$ \\
$r_{d c, z 3}=1.1946 \cdot 10^{-2} \Omega / \mathrm{km}$ & $l_{d c, z 3}=3.2942 \cdot 10^{-3} \mathrm{H} / \mathrm{km}$ \\
$g_{c s}=7.6333 \cdot 10^{-11} \mathrm{~S} / \mathrm{km}$ & $c_{c s}=1.9083 \cdot 10^{-7} \mathrm{~F} / \mathrm{km}$ \\
\hline
\end{tabular}

